\title{
The Relationship between Personality Traits and Psychological
}

\section{Resilience among the Caribbean Adolescents}

\author{
Grace Fayombo (PhD) \\ The University of the West Indies, Cave Hill Campus \\ School of Education, BB11000, Barbados \\ Tel: 246-257-3998Ｅ-mail: grace.fayombo@cavehill.uwi.edu
}

This research was funded by the Campus Research Award, Graduate Studies, The University of the West Indies, Cave Hill Campus, Barbados

\begin{abstract}
This cross-sectional study investigated the relationships between the big five personality traits: (conscientiousness, agreeableness, neuroticism, openness to experience, extraversion) and psychological resilience among 397 Caribbean secondary school adolescents. Pearson Product Moment Correlation and Stepwise Multiple Regressions were conducted to analyse the data. Results revealed statistically significant positive relationships between the personality traits (conscientiousness, agreeableness, openness to experience, extraversion) and psychological resilience, while neuroticism was negatively correlated with psychological resilience. The personality traits also jointly contributed $32 \%(\mathrm{R}$ square $=0.324)$ of the variance being accounted for in psychological resilience and this was found to be statistically significant with conscientiousness being the best predictor while agreeableness, neuroticism and openness to experience were other significant predictors, however, extraversion did not contribute significantly. These results are discussed in the light of healthy personality beefing up and promoting adolescents' psychological resilience.
\end{abstract}

Keywords: Psychological resilience, Conscientiousness, Agreeableness, Neuroticism, Openness to experience, Extraversion, Adolescence

\section{Introduction}

Adolescence is often characterised as a period of internal turmoil and external reckless when the adolescents smoke, take drugs, have sex and commit crimes to demonstrate their adulthood (Morffit, 1993). In addition, they have to contend with many developmental problems associated with this unique transitional stage (11 to 21 years) when they experience rapid and striking metamorphosis physically, emotionally, cognitively and socially (Schacter, Gilkbert \& Wegner, 2009). It is of great importance for them to maintain their mental health even while experiencing challenging events; in other words, resilience is required for them to be able to cope with the stress and especially for them to age out of the troubles they got themselves into (Sampson \& Laub, 1995) in order to transit successfully to adulthood stage. Hence, this study focuses on how personality traits can predict adolescents' psychological resilience.

\section{Psychological Resilience}

Evidence suggests that resilience is the process of capacity for, or outcome of successful adaptation despite challenging or threatening circumstances (Masten, Best and Garmezy, 1990) and that resilient adolescents are characterized by social competence, problem-solving skills, mastery, autonomy and a sense of purpose and future (Waters and Sroufe 1983; Rutter 1985; Werner and Smith 1987; Masten, Best and Garmezy 1990; Gore and Eckenrode 1994; Consortium on the School-Based Promotion of Social Competence 1994). In addition, resilient adolescents have high expectations, a meaning for life, goals, personal agency, and inter-personal problem-solving skills which work together to prevent the debilitating behaviors that are associated with learned helplessness (Bernard 1991). According to Theron (2004) and Barton (2005), resilient adolescents have inherent strengths that empower them to cope with adverse circumstances, referred to as protective factors which improve a person's response to some environmental hazards resulting in an adaptive outcome (Rutter, 1979). Such factors, which can reside within the individual or within the family or community, do not necessarily foster normal development in the absence of risk factors, but they may make an appreciable difference on the influence exerted 
by risk factors (IOM, 1994a). Adolescents who experience specific learning difficulties frequently exhibit few protective factors and struggle to adapt successfully when confronted by difficulty (Bauer, Keefe \& Shea, 2001), they are more vulnerable to failure and their inherent strengths or resilience skills are frequently lacking (Donald, Lazarus \& Lolwana, 2002) and in order to empower at-risk adolescents, prevention efforts are needed to promote protective factors and processes. Capable functioning in the face of adversity is linked to a triad of protective factors distinguished by Boyden \& Mann (2005) as:

Personal protective factors which are inherent in the resilient individual by virtue of either biological programming or temperamental attributes which include: innate factors such as autonomy, self-help skills and aptitude, self-efficacy and impulse control all geared towards strengthening the individual by buffering risk; familial protective factors (i.e. family factors including sound family structure and a supportive family network) and extra-familial protective factors (i.e. environmental factors including bonds with pro-social adults, positive peer relationships and effective schools).

If protective factors are to be harnessed to compensate for risk, to empower youth to rise to challenges which come their way and/or to moderate the impact of risk, it is necessary to understand precisely what makes youth resilient within a specific context (Boyden \& Mann, 2005). Thus, this research focuses on how healthy personality traits impact on adolescent's psychological resilience. Schacter, Gilbert \& Wegner (2009) posit that personality is an individual's characteristic style of behaving, thinking and feeling which arises from within the individual and remains fairly consistent throughout life. For the purpose of this study, The Big Five personality traits was used as the model for measuring the adolescents' personalities.

\section{The Big Five Personality Traits}

Literature suggests that The Big Five personality traits are five empirically supported dimensions of personality being used to describe personality which are; Openness, Conscientiousness, Extroversion, Agreeableness, and Neuroticism (OCEAN) or (CANOE) if arranged differently (Digman, 1990; Ewen, 1998; Srivastava,1999; The OCEAN of Personality, 2004). The term "Big Five" was coined by Goldberg (1993) and was originally associated with studies of personality traits used in natural language. The Big Five are so universal that they show up when people are asked to describe themselves (Passini \& Norman 1966) and they are associated with predictable patterns of behavior and social outcomes (John \& Srivastava, 1999). The Big Five traits are also known as the Five Factor Model (FFM) (Costa \& McCrae, 1992) which was first presented by the president of the American Psychological Association, Thurstone, (1933) and as the Global Factors of personality (Russell \& Karol, 1994). The term "Five-Factor Model" has been more commonly associated with studies of traits using personality questionnaires (McCrae \& Costa 1992) and personality investigators agree that personality is best captured by the five factor model rather than by two, three, sixteen or forty factor model (John \& Srivasta, 1999; McCrae \& Paul Costa 1992). These researchers asserted that the five factor model encompasses factors which are actually a cluster of more specific traits that are known to be statistically correlated such as:

\subsection{Conscientiousness personality}

People with conscientiousness personalities were found to be organized, thorough, they plan ahead and also related to impulse control, but it should not be confused with the problems of impulse control found in neuroticism. As reported by Costa \& McCrae (1992), people high on neurotic impulsiveness, find it difficult to resist temptation or delay gratification while individuals who are low on conscientious self-discipline are unable to motivate themselves to perform a task that they would like to accomplish. These are conceptually similar but empirically distinct. Similarly, Goleman (1997) pointed out that many of the behaviors associated with conscientiousness fall under the broad category of emotional intelligence and are frequently assessed by self-report integrity tests given by various corporations to prospective employees. For instance, considerable amount of research indicate that conscientiousness is one of the best predictors of performance in the workplace and conscientious employees are generally more reliable, more motivated and hard working (Salgado 1997).

\subsection{Agreeable personality}

Agreeableness measures how compatible people are with other people, or basically how able they are to get along with others. It is a tendency to be pleasant and accommodating in social situations reflecting individual differences in concern for cooperation and social harmony (Graziano \& Eisenberg 1997). Agreeable traits include empathetic, considerate, friendly, generous, and helpful and they also have an optimistic view of human nature. They tend to believe that most people are honest, decent, and trustworthy and less likely to suffer from social rejection (Bierman, 2003). Additionally, evidence have shown that whereas most people are likely to help their own kin, or empathise with them but contrarily, agreeable people are likely to help even when these 
conditions are not present (Graziano, Habashi, Sheese, \& Tobin 2007) thus being traited for helping and do not need any other motivations (Penner, Fritzsche, Craiger, \& Freifeld, 1995).

\subsection{Neurotic Personality}

Neuroticism has an inherent negative denotation (Bradshaw 1997) although (sometimes reversed and called Emotional Stability), an enduring tendency to experience negative emotional states and such feelings such as anxiety, anger, guilt, and depressed mood (Matthews \& Deary 1998). Similarly, Goleman (1997) found that they respond more poorly to environmental stress, are more likely to interpret ordinary situations as threatening and minor frustrations as hopelessly difficult. They are often self-conscious and shy, and they may have trouble controlling urges and delaying gratification. Neuroticism is associated with low emotional intelligence, which involves emotional regulation, motivation, and interpersonal skills. It is also a risk factor for "internalizing" mental disorders such as phobia, depression, panic disorder, and other anxiety disorders traditionally called neuroses (Hettema, Neale, Myers, Prescott, \& Kendler 2006). Individuals who are high in neuroticism may show more emotional reactions whenever confronted with stressful situations (Van Heck, 1997). Moreover, they seem to use avoiding and distracting coping strategies, such as denying, wishful thinking, and self-criticism, rather than more approaching strategies (Bolger, 1990; Heppner et al., 1995; McCrae \& Costa, 1986). Ineffective coping with stressful situations in the work environment makes individuals who are high in neuroticism more vulnerable to the symptoms that are typically associated with burnout (Bakker, Van der Zee, Lewig \& Dollard 2006).

\subsection{Openness to Experience}

Openness to Experience (sometimes called Intellect or Intellect/Imagination) refers to how willing people are to make adjustments in notions and activities in accordance with new ideas or situations (Goldberg, 1993; McCrae, \& John, 1992). It includes traits like having wide interests, being imaginative, insightful, attentiveness to inner feelings, preference for variety, and intellectual curiosity (Costa, \& McCrae, 1992). Researchers have demonstrated that people who are highly open to experience tend to be politically liberal and tolerant of diversity (McCrae 1996; Jost, 2006). As a consequence, they are generally more open to different cultures and lifestyles. They are lower in ethnocentrism and right-wing authoritarianism. There is no relationship between openness and neuroticism, or any other measure of psychological wellbeing. Being open and closed to experience are simply two different ways of relating to the world (Butler 2000).

\subsection{Extraversion}

Extraversion (sometimes called Surgency), also referred to as social adaptability, though the popularity of this term seems to be waning (Zuckerman, 1991). Extraversion is the act, state, or habit of being predominantly concerned with and obtaining gratification from what is outside the self, defined as "a trait characterized by a keen interest in other people and external events, and venturing forth with confidence into the unknown (Ewen, 1998).The broad dimension of extraversion encompasses such more specific traits as talkative, energetic, gregarious and assertiveness.

\section{Big Five Personality traits and psychological resilience.}

There is considerable evidence that these personality traits can influence psychological resilience among the adolescents as found in earlier studies. For instance, Campbell-Sills, Cohan, \& Stein, (2006) reported that resilience was negatively associated with neuroticism, and positively related to extraversion and conscientiousness. In their assessment of some undergraduates' capacity to successfully adapt despite challenging or threatening circumstances, Makaya , Oshio \& Kaneko (2006) also found significant negative correlation between adolescents' resilience and the Neuroticism dimension of the Big Five Personality Inventory, and positive values with the Extraversion, Openness, and Conscientiousness dimensions. Similarly, using Big Five to discriminate between well adjusted and more vulnerable personality profiles, Annalakshmi (2007) found that all resilience factors were positively correlated with the well adjusted personality profile obtained. It was also reported that individuals scoring high on resilience scale are psychologically healthier, better adjusted, and thus more resilient (Friborg, Barlaug, Martinussen, Rosenvinge \& Hjemdal 2005). The earlier findings report that the resilient children have superior reasoning and problem solving skills (Dubow \& Luster, 1990; Werner, 1989a; Werner,1990). Resilient children were also reported to display high intellectual motivation and a probing drive to understand (Murphy \& Moriarty, 1976). The resilient children are further reported to mediate their own learning and problem-solving by taking the initiative and that resilience is not a permanent capacity but is a dynamic construct (Winfield, 1991). Annalakshmi (2008), analysing the relationship between personality and resilience further confirms that personality traits like exhibitionism, impulsivity and understanding contribute to resilience, and being resilient enhances the personality traits. Thus resilient personality is being driven by certain secondary 
needs and the extent to which each of these needs was felt by an individual shaped their personality and behavior. This explains the dynamics of resilient personality (Annalakshmi 2008).

Other investigators who studied different measures of psychological resilience such as, burnout coping and hardiness further confirmed the findings just cited. For instance, Bakker, Van der Zee, Lewig \& Dollard (2006) reported that significant relationship exist between burnout and the 5 basic (Big Five) personality factors (a) emotional exhaustion is uniquely predicted by emotional stability; (b) depersonalization is predicted by emotional stability, extraversion, and intellect/autonomy; and (c) personal accomplishment is predicted by extraversion and emotional stability among 80 volunteer counselors who cared for terminally ill patients. Zhang (2010) also indicated that personality traits statistically predicted hardiness beyond age and gender among Chinese university students.

\section{Present Study}

Based on the available literature, it is evident that the big five and other personality traits significantly influence psychological resilience often described as adaptation, coping (Goleman 2006), and hardiness (Seligman 1998), but reports regarding which of the personality traits best predicts psychological resilience are inconsistent. However, as inconsistent as they are, these findings had indicated that healthy personality factors are important in determining resilient individual, yet this study has not been carried out among the secondary school adolescents in the Caribbean in order to understand their inherent ability to cope with stress (psychological resilience) and academic problems based on their personality make up. It is against this backdrop that the present study was posited.

\section{Aim of Study}

Specifically therefore the aims of this study were threefold:

1) To find out the relationships between the big five personality traits (conscientiousness, agreeableness, neuroticism, openness to experience, extraversion) and psychological resilience among the secondary school Caribbean adolescent sample.

2) Secondly, using the Big Five Personality traits as a framework, the researcher wanted to get a clear picture of how each of the traits, will significantly predict psychological resilience among the secondary school Caribbean adolescent sample.

3) To predict the combined contributions of the personality traits to the variance in psychological resilience.

\section{Method}

\subsection{Participants}

There was a random sampling of 397 fourth to upper sixth form adolescents from six secondary schools in different parishes in Barbados. Their ages ranged from 14 to 18 years old $(M=15.52, S D=1.21)$; 205 were females and 192 were males, of which 220 were Barbadians while 177 were from a number of Caribbean countries: Guyana, St Vincent, St Lucia and Jamaica.

\subsection{Measures}

The participants completed two instruments:

Big Five Personality Measure. The personality traits conscientiousness, agreeableness, neuroticism, openness to experience and extraversion were measured utilizing the 50-item International Personality Item Pool (IPIP) (Goldberg et al., 2006). The measure has five factors consisting of five-point likert-type items with corresponding values of 1 - very inaccurate; 2 - moderately inaccurate; 3 - neither inaccurate nor accurate; 4moderately accurate; 5- very accurate for positive items which were reversed and for the negative items measuring each facet: conscientiousness $\alpha=.79$; extraversion $\alpha=.87$; agreeableness $\alpha=.82$; openness to experience $\alpha=.84$; neuroticism $\alpha=.86$ ). The higher the score, the more healthy the personality trait.

Psychological Resilience Measure was constructed by the researcher. It has two sections that assessed: (1) adolescents' demographics, sex, age, school, class (2) the adolescents' psychological resilience via a 15- item scale, with response anchors ranging from strongly agree (4) to strongly disagree (1). The scale has a theoretical value ranging between 15 and 60 and consists of seven positively worded and eight negatively worded items such as: - 'I am calm in stressful situations', 'My future is mostly in the hands of other people'. The higher the score, the stronger the resilience. The items were generated during the review of literature and the initial versions 
were given to experts for suggestions and comments before coming up with the final version with the Cronbach alpha reliability coefficient of 0.79 .

\subsection{Procedure}

Informed consents for the students to participate in the survey were obtained from their parents and the school principals. The adolescents were surveyed in their school halls by the researcher with the assistance of the school principals, the teachers and the school guidance counsellors. The researcher took time to brief the participants on the process of answering the items in the questionnaires. For instance, the participants were told that there are no "right" or "wrong" answers, but they should note that meaningful results will not be obtained unless they answer the questions correctly and seriously and that the results are being used in scientific research, so they should please try to give accurate answers. The students were informed that the information would remain confidential and to buttress this, they were told not to write their names. The administration of the instruments lasted for approximately one hour.

\section{Data Analysis}

Pearson Product Moment Correlation and Stepwise Multiple Regressions were conducted to analyse the data. All the negatively worded items were reversed during analysis.

\section{Results}

The first aim of this research was to find out the relationships between the personality traits and psychological resilience. The statistically significant positive and negative correlations among the variables and psychological resilience are presented in Table 1. Conscientiousness significantly and positively correlated with psychological resilience $(r=0.459, p<0.05)$; agreeableness with psychological resilience $(r=0.317, p<0.05)$; openness to experience with psychological resilience $(r=0.235, p<0.05)$; extraversion with psychological resilience $(r=0.183$, $p<0.05)$; while neuroticism, significantly and negatively correlated with psychological resilience $(r=-0.288$, $p<0.05)$.

These statistically significant positive correlations indicated that the healthier the personality traits, the more resilient the adolescent. The negative associations between neuroticism and psychological resilience however indicated that adolescents who have unhealthy personality such as neuroticism may not be psychologically resilient. These relationships among the personality traits and psychological resilience are also illustrated in Figure 1 .

There were also significant positive and negative associations among the variables thus: Conscientiousness correlated with agreeableness $(r=0.146, p<0.05)$; conscientiousness negatively correlated with neuroticism $(r=$ $-0.206, p<0.05)$; conscientiousness personality was associated with openness to experience $(r=0.142, p<0.05)$ but did not correlate with extraversion; indicating that a learner who is organized, thorough and plans ahead is also likely to get along with others, may not be anxious or experience depressed mood, is likely to be intellectually curious but may not be talkative. Additionally, agreeableness correlated with openness to experience $(r=0.297, p<0.05)$ and extraversion $(r=0.285, p<0.05)$ but did not correlate with neuroticism, indicating that an adolescent that is considerate may probably adjust to new ideas and be assertive but may not be outgoing. Likewise, neuroticism did not correlate with openness and extraversion, indicating that an adolescent who displays angry and anxious personality may not be intellectually curious and even be popular; openness however correlated with extraversion $(r=0.308, p<0.05)$ meaning that an adolescent who is insightful may likely be assertive.

\section{Insert Table 1 here}

\section{Insert Figure 1 here}

The second aim of this study was to estimate the relative contributions of the predictor variables to the variance in psychological resilience. To this end, stepwise regression analysis was computed with psychological resilience as the dependent measure and the personality traits being the predictors as seen in Table 2. Conscientiousness was entered first to find out how much variability it could significantly account for, followed by agreeableness, neuroticism, openness to experience and lastly extraversion was added to know if the amount of explained variability would significantly increase when each of them are included.

As can be seen in Table 2, Step 1, conscientiousness alone accounted for $21 \%$ (R Square $=0.211)$ of the variance in psychological resilience, the inclusion of agreeableness in Step 2 accounted for $28 \%$ (R square $=0.275$ ) which resulted in additional $7 \%$ of the variance, in Step 3, the inclusion of neuroticism accounted for $31 \%$ (R square $=$ 0.308 ) which resulted in additional $3 \%$ of the variance being explained, in step 4 , the inclusion of openness to 
experience accounted for $32 \%(\mathrm{R}$ square $=0.324)$ which resulted in additional $1 \%$ of the variance in psychological resilience. In Step 4 also, the standardised $\beta$ and the unstandardised $b$ values reveal the decreasing order of the predictors: conscientiousness $>$ agreeableness $>$ neuroticism $>$ openness to experience showing that conscientiousness was the best predictor, followed by agreeableness, neuroticism and openness to experience. Thus, psychological resilience is significantly predicted by conscientiousness, $(\beta=0.37, p<0.01)$, by agreeableness, $(\beta=0.21, \mathrm{p}<0.01)$, by neuroticism $(\beta=-0.19, \mathrm{p}<0.05)$ and openness to experience $(\beta=0.12$, $\mathrm{p}<0.05$ ). Surprisingly, the inclusion of extraversion did not make any significant difference, therefore it was not included in the model.

Insert Table 2 here

The final aim of this study was to find out the combined contributions of the big five personality traits to the variance in psychological resilience. These predictors accounted for 32\% ( R Square $=0.324)$ of the variance in psychological resilience as seen in Table 2. Using the stepwise method, therefore, a significant model emerged, $(\mathrm{F}(5,391)=37.53, \mathrm{p}<.0005)$. The model explains $32 \%$ of the variance $(\mathrm{R}$ square $=0.324)$. Table 2 gives information for the predictor variables entered into the model. Extraversion was not a significant predictor but the other four personality traits were. Therefore, psychological resilience is partially predicted by the big five personality traits.

\section{Discussion}

This study investigated the relationship between the big five personality traits and psychological resilience among the secondary school Caribbean adolescent sample. It was found that significant positive associations existed between the psychological traits (conscientiousness, agreeableness, extraversion, openness to experience) and psychological resilience. However, neuroticism was negatively associated with psychological resilience. This is quite expected because conscientiousness, agreeableness, openness to experience and extraversion are healthy personalities with such traits as hard working, getting along with others, intellectually curious and assertiveness. All these promote psychological resilience in an individual while those of neuroticism like nervousness negates it. Thus, the healthier the personality, the more the resilience. This lends credence to previous findings that negative correlation existed between adolescent resilience and the neuroticism dimension of the big five personality inventory, and positive values with the Extraversion, Openness, and Conscientiousness dimensions (Makaya, Oshio \& Kaneko 2006).

In the present study, the adolescents who exhibited conscientiousness personality traits like; always being prepared, getting chores done right away and paying attention to details were found to be resilient indicating that probably they are usually calm in stressful situations which strengthens their inherent ability to cope with stress. This supports the earlier report by Goleman (1997) that many of the behaviors associated with conscientiousness such as being organized, thorough and planning ahead fall under the broad category of emotional intelligence which promote resilience in adolescence. Likewise adolescents with agreeable personality, who reported being empathetic, interested in people, friendly, considerate and generous were also found to be resilient probably because they have an optimistic view of human nature, they are full of hope and they are confident in successful outcome of their actions and future. This finding supports the existing literature that agreeable personalities are likely to help even when conditions are not pleasant (Graziano, Habashi, Sheese, \& Tobin 2007) and thus being "traited for helping and do not need any other motivations (Penner, Fritzsche, Craiger, \& Freifeld, 1995).

The adolescents who were opened to experience in this study, reported being full of excellent ideas, have a rich vocabulary and spend time reflecting on things also tended to be resilient probably because they are able to adjust to new ideas or situations as earlier suggested by Costa, \& McCrae, (1992); McCrae, \& John, (1992), that adolescents, who are intellectually curious, having wide interests, being imaginative, insightful, attentive to inner feelings, are also likely to be resilient because they tend to make adjustments in notions and activities in accordance with new ideas or situations (Goldberg, 1993; McCrae, \& John, 1992). Furthermore, the extraverts in this study, who are outgoing, who feel comfortable around people, who start conversations, also tended to be resilient. This corroborates the earlier findings that they have keen interest in other people and external events, (Ewen, 1998) and venture with confidence into the unknown and they socially adapt to situations (Zuckerman, 1991).

That neuroticism was negatively associated with psychological resilience and other predictor variables is not surprising as well. This finding confirmed the earlier literature that neuroticism has an inherent negative denotation (Bradshaw 1997) which is associated with negative emotional states and feelings such as anxiety, anger, guilt, and depressed mood (Matthews \& Deary 1998). In the present study, the adolescents with neurotic personality reported being stressed easily and worrying about things and as a result of these, they may not be 
resilient probably because of their poor reactions to environmental stress and are more likely to interpret ordinary situations as threatening and minor frustrations as hopelessly difficult as earlier reported by Goleman (1997). In addition, because of their anxiety and worries, the adolescents with neurotic behaviours tended to be less resilient than their conscientious, agreeable, openness and extraverted traited counterparts because they are likely to see life difficulties as insurmountable problems which are likely to be addressed as normal challenges of life by their counterparts.

In addition, the negative correlation between neuroticism and conscientiousness further confirms the existing literature that people high on neurotic impulsiveness find it difficult to resist temptation or delay gratification while individuals who are low on conscientious self-discipline are unable to motivate themselves to perform a task that they would like to accomplish (Costa \& McCrae 1992). This finding also corroborates the earlier reports that neuroticism is associated with low emotional intelligence, (Hettema, Neale, Myers, Prescott, \& Kendler 2006) while many of the behaviors associated with conscientiousness fall under the broad category of emotional intelligence (Goleman 1997). No correlations were found between neuroticism and openness to experience, agreeableness and extraversion, again, this further supports the earlier reports that there is no relationship between openness and neuroticism, or any other measure of psychological wellbeing in that open and closed to experience are simply two different ways of relating to the world (Butler 2000).

Of special interest is the present finding that conscientiousness, agreeableness, openness to experience and neuroticism relatively predicted psychological resilience but extraversion did not significantly predict it among this Caribbean adolescent sample. This finding is amazing because extraverts are characterized with traits such as enthusiasm, talkative, energetic, assertiveness and venturing forth with confidence into the unknown (Ewen, 1998) which are essential for psychological resilience, but in spite of these, it did not contribute significantly to the variance in psychological resilience. A probable explanation for this may be due to the fact that extraverts have traits that enhance their physical well being, they focus on the external world around them and are likely to be less concerned with internal and inherent capability that will engender psychological resilience which also calls for endurance on the part of the individual. Moreover, this outgoing and restless nature of the extraverts are typical of the adolescent stage and may be responsible for not contributing significantly to the variance in psychological resilience.

The finding of this study also indicated that conscientiousness is the best predictor of psychological resilience among this adolescent sample, followed by agreeableness, neuroticism and openness to experience indicating that the adolescents with conscientious personality traits are likely to be more resilient than adolescents with agreeable and openness personalities and those with neurotic personality. This amplified the earlier report that conscientiousness is one of the best predictors of performance in the workplace and conscientious employees are generally more reliable, more motivated, and hard working (Salgado 1997); openness to experience (sometimes called Intellect or Intellect/Imagination) personality makes adjustments in notions and activities in accordance with new ideas or situations (Goldberg, 1993; McCrae, \& John, 1992) and that agreeable personality are also flexible to different situations and different people and are less likely to suffer from social rejection (Bierman, 2003). However, neuroticism is a risk factor for "internalizing" mental disorders such as phobia, depression, panic disorder, and other anxiety disorders traditionally called neuroses (Hettema, Neale, Myers, Prescott, \& Kendler, 2006), hence its negative prediction of psychological resilience.

The final result of this study confirms that the personality traits jointly accounted for $32 \%$ (R Square $=0.324$ ) of the variance being explained in psychological resilience and this was found to be significant $(\mathrm{F}(5,391)=37.53$, $\mathrm{p}<.0005)$, which is an evidence that the model that emerged is fit and it has the ability to predict adolescents' psychological resilience. This lends credence to the earlier report that in a risk-protective model of resilience, a protective factor interacts with a risk factor to mitigate the occurrence of a negative outcome (Zimmerman, Ramirez-Vales, Maton 1999) by neutralising the effect of the risk factor (Donald, Lazarus \& Lolwana, 2002). Suffice to say that the personality traits (conscientiousness, agreeableness, and openness to experience, and neuroticism which is emotional stability when reversed) are healthy personality traits which are protective in nature, hence they tend to protect psychological resilience among the adolescents while attenuating risks that may negate resilience in adolescence which may also prevent them from successfully transiting to adulthood. Though extraversion was not a significant predictor, but the other four personality traits were, therefore, psychological resilience was significantly predicted by the big five personality traits.

\section{Conclusion}

This study had indicated that healthy personality traits are important factors in determining Caribbean adolescents' psychological resilience. The model that emerged from the study also provided insight into the 
ways that healthy personalities can promote adolescents' wellbeing, while unhealthy one like neuroticism can negate it. The findings of this study are also useful for parents, psychologists, school guidance counselors and social workers in aiding their understanding of adolescents' behaviours and helping them achieve more academically and transit successfully to adulthood stage. The order of the significant relationships with conscientiousness being the best predictor, followed by agreeableness, neuroticism, openness and extraversion provided an interesting theoretical link with the prior investigators who had referred to the personality traits as CANOE as well as Thurstone's (1933) and Goldberg's (1993) Big Five personality traits and previous models on psychological resilience. These results also provide evidence-based support for the growing body of research surrounding these personality traits. However, further researches can be conducted to predict adolescents' psychological resilience by other personality traits not covered by the big five personality traits to further expand the existing literature in these areas.

\section{References}

Annalakshmi, N. (2007). Resilience in relation to Extraversion-Introversion, Psychoticism and Neuroticism. Indian Journal of Psychometry \& Education, 38, 51-55.

Annalakshmi, N. (2008). The Resilient Individual: A Personality Analysis. Journal of the Indian Academy of Applied Psychology, 34, 110-118

Bakker, A. B., Van der Zee, K. I., Lewig, K. A., \& Dollard, M. F. (2006). The relationship between the Big Five personality factors and burnout: a study among volunteer counselors. Journal of Social Psycholology, 146(1): $31-50$

Barton, W.H. (2005). Methodological challenges in the study of resilience. In: Ungar M (ed.). Handbook for working with children and youth. Pathways to resilience across cultures and context. California: Sage Publications.

Bauer, A.M., Keefe, C.H., \& Shea, T.M. (2001). Students with Learning Disabilities or Emotional/Behavioral Disorders. Upper Saddle River, N.J: Merrill/Prentice Hall.

Benard, B. (1991). Fostering resiliency in kids: Protective factors in the family, school and community. Portland, Oregon: Western Center for Drug-Free Schools and Communities

Bierman, K. L. (2003). Peer rejection: Developmental processes and intervention strategies. New York: The Guilford Press.

Bolger, N. (1990). Coping as a personality process: A prospective study. Journal of Personality and Social Psychology, 59, 525-537.

Boyden, J., \& Mann, G. (2005). Children's risk, resilience and coping in extreme situations. In: Ungar M (ed.). Handbook for working with children and youth. Pathways to resilience across cultures and contexts. California: Sage Publications.

Butler, J. C. (2000). Personality and emotional correlates of right-wing authoritarianism. Social Behavior and Personality, 28, 1-14.

Campbell-Sills,L., Cohan, S.L., \& Stein, M. (2006). Relationship of resilience to personality, coping, and psychiatric symptoms in young adults. Behaviour Research and Therapy, 44(4), 585-599 .

Consortium on the School-Based Promotion of Social Competence. (1994). The school-based promotion of social competence: theory, research, practice and policy. In R. Haggerty et al. (Eds) Stress, Risk and Resilience in Children and Adolescents: Processes, Mechanisms and Interventions. New York: Cambridge University Press.

Costa, P.T., \& McCrae, R.R. (1992). Revised NEO Personality Inventory (NEO-PI-R) and NEO Five-Factor Inventory (NEO-FFI) manual. Odessa, FL: Psychological Assessment Resources.

Digman, J.M. (1990). Personality structure: Emergence of the five-factor model. Annual Review of Psychology, $41,417-440$

Digman, J.M. (1989). Five robust trait dimensions: Development, stability, and utility. Journal of Personality, 57(2), 195-214.

Donald, D., Lazarus, S., \& Lolwana, P. (2002). Educational Psychology in Social Context. Cape Town: Oxford University Press.

Ewen, R. B. (1998). Personality: A topical approach. Mahweh, NJ: Erlbaum. 
Friborg, O., Barlaug, D., Martinussen, M., Rosenvinge, J.H., \& Hjemdal, O. (2005). Resilience in relation to personality and intelligence. International Journal of Methods in Psychiatric Research, 14 (1), 29-42.

Garmezy, N. \& Rutter, M. (1983). Stress, Coping, and Development in Children. New York:McGraw-Hill.

Garmezy, N. (1993). Children in poverty: Resilience despite risk. Psychiatry, 56, 127-136.

Goldberg, L. R. (1993). The structure of phenotypic personality traits. American Psychologist, 48, 26-34.

Goldberg, L.R. (1982). From Ace to Zombie: Some explorations in the language of personality. In C.D. Spielberger \& J.N. Butcher (Eds.), Advances in personality assessment, Vol. 1. Hillsdale, NJ: Erlbaum

Goldberg, L. R., Johnson, J. A., Eber, H. W., Hogan, R., Ashton, M. C., Cloninger, C. R., \& Gough, H. C. (2006). The International Personality Item Pool and the future of public-domain personality measures. Journal of Research in Personality, 40, 84-96.

Goleman, D. (1997). Emotional Intelligence. New York: Bantam

Gore, S., and Eckenrode, J. (1994) Context and process in research on risk and resilience. In R. Haggerty et al. (Eds.) Stress, Risk and Resilience in Children and Adolescents: Processes, Mechanisms and Interventions. New York: Cambridge University Press.

Gordon, K. A. (1995). The self-concept and motivational patterns of resilient African American high school students. Journal of Black Psychology, 21, 239-255

Graziano, W.G., \& Eisenberg, N. (1997). Agreeableness; A dimension of personality. In R. Hogan, S. Briggs, \& J. Johnson, (1997). Handbook of Personality Psychology. San Diego, CA: Academic Press

Graziano, W. G., Habashi, M. M., Sheese, B.E., \& Tobin, R. M. (2007). Agreeableness, empathy, and helping: A person X situation perspective. Journal of Personality and Social Psychology.

Heppner, P. P., Cook, S. W., Wright, D. M., \& Johnson, W. C., Jr. (1995). Progress in resolving problems: A problem-focused style of coping. Journal of Counseling Psychology,42, 279-293.

Hettema, J. M., Neale, M. C., Myers, J. M., Prescott, C. A., \& Kendler, K. S. (2006). A population-based twin study of the relationship between neuroticism and internalizing disorders. American journal of Psychiatry, 163, 857-864.

Institute of Medicine. (1994a). Reducing risks for mental disorders: Frontiers for preventive intervention research. Washington, DC: National Academy Press

John, O. P., \& Srivastava, S. (1999). The Big-Five trait taxonomy: History, measurement, and theoretical perspectives. In L. A. Pervin \& O. P. John (Eds.), Handbook of personality: Theory and research (Vol. 2, pp. 102-138). New York: Guilford Press.

John, O. P., Naumann, L. P., \& Soto, C. J. (2008). Paradigm Shift to the Integrative Big-Five Trait Taxonomy: History, Measurement, and Conceptual Issues. In O. P. John, R. W. Robins, \& L. A. Pervin (Eds.), Handbook of personality: Theory and research (pp. 114-158). New York, NY: Guilford Press.

Jost, J. T. (2006). The end of the end of ideology. American Psychologist, 61, 651-670.

Lounsbury, J.W. (2004). An investigation of personality traits in relation to intention to withdraw from college. Journal of College Student Development, 45, 517-534.

Luthar, S. (1991). Vulnerability and resilience: A study of high-risk adolescents. Child Development, 62, 600-616.

Masten, A., Best, K., \& Garmezy, N. (1990). Resilience and development: Contributions from the study of children who overcome adversity. Development and Psychopathology, 2, 425-444.

Matthews, G., and Deary, I. J. (1998). Personality traits. Cambridge, UK: Cambridge University Press..

McCrae, R. R., \& Costa, P. T., Jr. (1986). Personality, coping, and coping effectiveness in an adult sample. Journal of Personality, 54, 385-405.

McCrae, R. R., \& John, O. P. (1992). An introduction to the Five-Factor Model and its applications. Journal of Personality, 60, 175-215.

McCrae, R. R. (1996). Social consequences of experiential openness. Psychological Bulletin, 120, 323-337.

Morffit, T. E. (1993). Adolescence -limited and life-course-persistent antisocial behavior: A developmental taxonomy. Psychological Review, 100, 674-701 
Murphy, L., \& Moriarty, A. (1976). Vulnerability, coping, and growth from infancy to adolescence. New Haven: University Press

Nakaya M, Oshio A, Kaneko H. (2006). Correlations for Adolescent Resilience Scale with big five personality traits. Psychological reports. 98(3), 927-30.

Norman, W.T., \& Goldberg, L.R. (1966). Raters, ratees, and randomness in personality structure. Journal of Personality and Social Psychology, 4, 681-691.

Oliver ,P. J and Srivastava, S. (1999). The Big-Five Trait Taxonomy: History, Measurement, and Theoretical Perspectives. In L. A. Pervin \& O. P. John (Eds.), Handbook of personality: Theory and research (2nd ed.), pages 102-139, New York: Guilford Press,

Penner, L. A., Fritzsche, B. A., Craiger, J. P., \& Freifeld, T. S. (1995). Measuring the prosocial personality. Advances in Personality Assessment, 10, 147-163.

Russell, M.T., \& Karol, D. (1994). 16PF Fifth Edition administrator's manual.Champaign, IL: Institute for Personality \& Ability Testing.

Rutter, M., Maughan, B., Mortimore, P., and Ouston, J. (1979). Fifteen Thousand Hours: Secondary Schools and their Effects on Children. Cambridge: Harvard University Press

Salgado, F. (1997). The five factor model of personality and job performance in the European community. Journal of Applied Psychology, 82 (1): 30-43

Sampson, R. J., \& Laub, J. H. (1995). Understanding variability in lives through time: Contributions of the life-course, criminology. Studies of Crime Intervention. 4, 153 -158.

Schacter, D. L., Gilbert, D.T., \& Wegner D. M. (2009). Psychology. Worth Pubblishers, New York.

Srivastava, S. (2010). Measuring the Big Five Personality Factors. [Online] available http://www.uoregon.edu/ sanjay/bigfive.html (July 7, 2010)

The OCEAN of Personality synopsis, Chapter 4: Trait Theory. All Psych Online. Last updated March 23, 2004 [Online] available http://allpsych.com/personalitysynopsis/trait_application.html (August 8, 2010)

Theron LC. (2004). The role of personal protective factors in anchoring psychological resilience in adolescents with learning difficulties. South African Journal of Education, 24:317-321

Thurstone, L. L. (1933). The theory of multiple factors. Address of the president before the American Psychological Association, Chicago meeting, The vectors of the mind. First published in Psychological Review, 41, 1-32. [Online] Available http://psychclassics.yorku.ca/Thurstone/ (August 2, 2010)

Waters, E., and Sroufe, L.A. (1983). Social competence as a developmental construct, Developmental Review, 3 , $779-797$.

Werner, E., and Smith, R. (1987). Vulnerable but Invincible: A Longitudinal Study of Resilient Children and Youth. New York: Adams, Bannister and Cox.

Werner, E. E. (1989a). High-risk children in adulthood: A longitudinal study from birth to 32 years. American Journal of Orthopsychiatry, 59, 72-81.

Zhang, L. (2010). Hardiness and the Big Five personality traits among Chinese university students.Learning and Individual Difference Article in Press. doi: 10. 1016/j.lindif.2010.05.006 [Online] Available: http://www.sciencedirect.com/science?_ob=MImg\&_imagekey=B6W5P-508CGTC-(July 10, 2010)

Zimmerman, M.A, Ramírez-Valles, J., and Maton, K. I. (1999). Resilience among Urban African American Male Adolescents: A Study of the Protective Effects of Socio-Political Control on their Mental Health. American Journal of Community Psychology, 27(6):733-51.

Zuckerman, M. (1991). Psychobiology of personality. New York: Cambridge University Press. 
Table 1. Correlation Matrix of Psychological resilience, Conscientiousness, Agreeableness, Neuroticism, Openness to Experience and Extraversion

\begin{tabular}{l|rrrrrr}
\hline Variables & Psy Res & Conscien & Agree & Neuro & Openness & Extraver \\
\hline Psychological Resilience & \multicolumn{1}{|c}{-} & & & & & \\
Conscientiousness & $0.459^{* *}$ & - & & & & \\
Agreeableness & $0.317^{* *}$ & $0.146^{* *}$ & - & & \\
Neuroticism & $-0.288^{* *}$ & $-0.206^{* *}$ & -0.084 & - & & \\
Openness to Experience & $0.235^{* *}$ & $0.142^{* *}$ & $0.297^{* *}$ & -0.007 & - & \\
Extraversion & $0.183^{* *}$ & 0.082 & $0.285^{* *}$ & -0.008 & $0.308^{* *}$ & - \\
\hline
\end{tabular}

**Significant $(p<0.01)$

Table 2. Stepwise Regression Analysis Predicting Students' Psychological Resilience

\begin{tabular}{l|l|l|l|l}
\hline Predictors & $\mathrm{b}$ & $\beta$ & $\Delta \mathrm{R}^{2}$ & $\mathrm{t}$ \\
\hline Step 1 & & & & \\
\hline Conscientiousness & 0.32 & $0.46^{* *}$ & $0.21^{* *}$ & 10.28 \\
\hline Step 2 & & & & \\
\hline Conscientiousness & 0.29 & $0.42^{* *}$ & & 9.73 \\
\hline Agreeableness & 0.17 & $0.26^{* *}$ & $0.07^{* *}$ & 5.88 \\
\hline Step 3 & & & & \\
\hline Conscientiousness & 0.27 & $0.39^{* *}$ & & 8.89 \\
\hline Agreeableness & 0.17 & $0.25^{* *}$ & & 5.77 \\
\hline Neuroticism & 0.09 & $-0.19^{*}$ & $-0.03^{*}$ & -4.38 \\
\hline Step 4 & & & & \\
\hline Conscientiousness & 0.26 & $0.37^{* *}$ & & 8.61 \\
\hline Agreeableness & 0.14 & $0.21^{* *}$ & & 4.81 \\
\hline Neuroticism & -0.10 & $-0.19^{*}$ & & 4.52 \\
\hline Openness to Experience & 0.68 & $0.12^{*}$ & $0.01^{*}$ & 2.68 \\
\hline
\end{tabular}

Note: $* * \mathrm{p}<.001, * \mathrm{P}<.01$ 


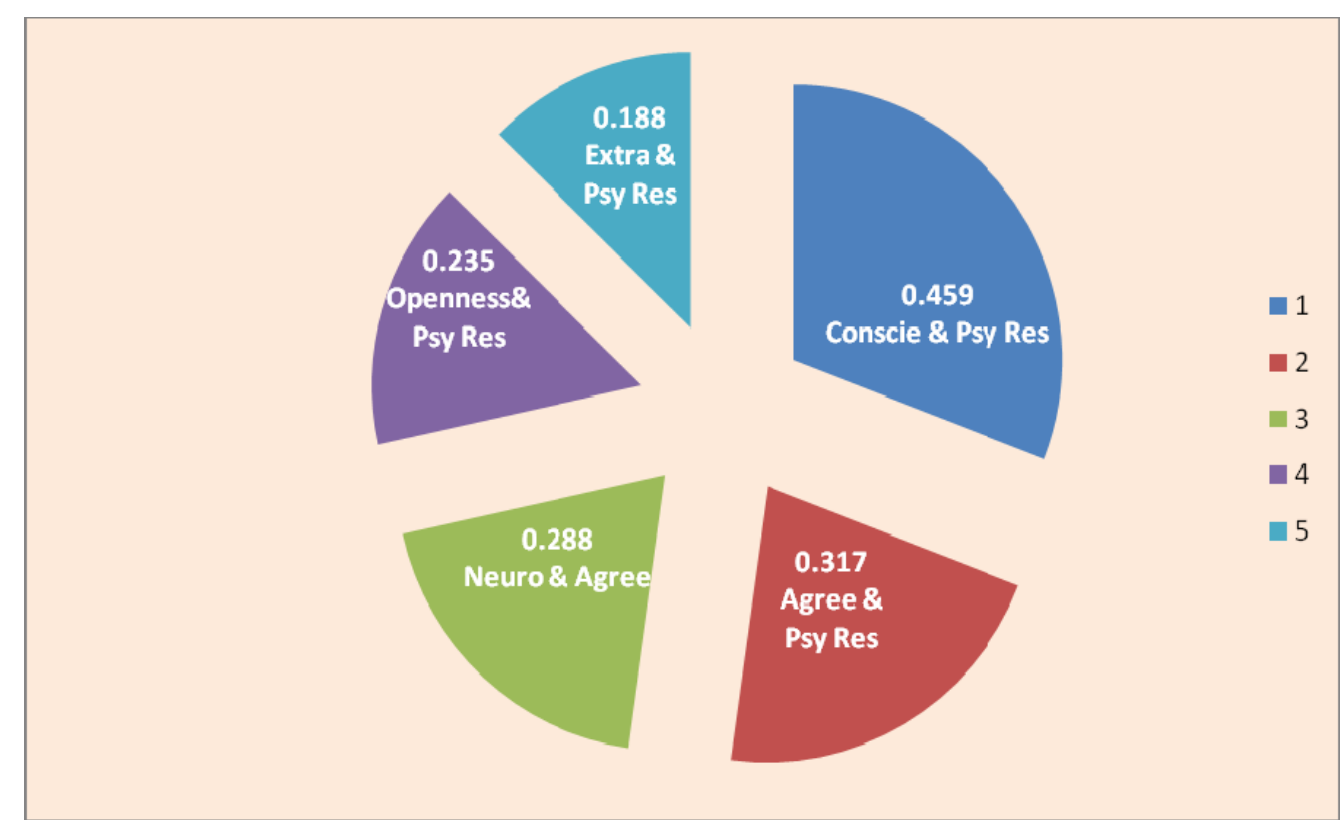

Figure 1. Relationships among Conscientiousness, Agreeableness, Neuroticism, Openness to Experience, Extraversion and Psychological Resilience 